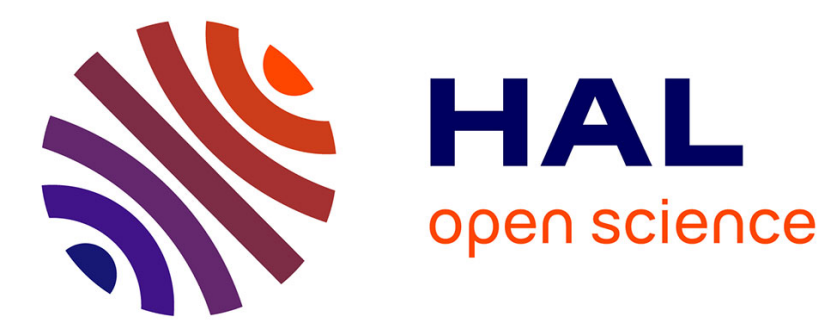

\title{
Mirage: a new proton facility for the study of direct ionization in sub-100 $\mathrm{nm}$ technologies
}

\author{
S. Duzellier, G. Hubert, R. Rey, F. Bezerra
}

\section{To cite this version:}

S. Duzellier, G. Hubert, R. Rey, F. Bezerra. Mirage: a new proton facility for the study of direct ionization in sub-100 nm technologies. NSREC 2014, Jul 2014, PARIS, France. hal-01070303

\section{HAL Id: hal-01070303 \\ https://hal-onera.archives-ouvertes.fr/hal-01070303}

Submitted on 1 Oct 2014

HAL is a multi-disciplinary open access archive for the deposit and dissemination of scientific research documents, whether they are published or not. The documents may come from teaching and research institutions in France or abroad, or from public or private research centers.
L'archive ouverte pluridisciplinaire HAL, est destinée au dépôt et à la diffusion de documents scientifiques de niveau recherche, publiés ou non, émanant des établissements d'enseignement et de recherche français ou étrangers, des laboratoires publics ou privés. 


\title{
Mirage: a new proton facility for the study of direct ionization in sub-100nm technologies
}

\author{
S. Duzellier, G. Hubert, R. Rey and F. Bezerra
}

\begin{abstract}
A new proton beam line has been developed at ONERA for investigating radiation effects in electronics. Standard beams are used for studying cumulated effects in optoelectronics and photonics, low current configuration has been developed for studying direct ionization effects in advanced digital technologies.
\end{abstract}

\section{INTRODUCTION}

Direct ionization from protons has recently been identified as a new SEE mechanism in highly integrated technologies [1]-[4]. Experimental evidence of this phenomenon in $65 \mathrm{~nm}$ memories has first been reported by IBM showing the importance of the position of the Bragg peak into the sensitive volume. Associated to direct ionization, well-known (with heavy ions) incidence angle effects are also observed. Similar results can also be found in [3]-[4] and show that low energy protons can induced SEUs respectively in $90 \mathrm{~nm}$ bulk CMOS and $45 \mathrm{~nm}$ SOI SRAMs. These results clearly indicate that the investigated devices are sensitive to the direct ionization of proton with ground testing conditions.

The main objective is to quantify the impact in a realistic and operational environment. Thus, the impact of direct ionization on flight rate, including space and avionic environment, has also been investigated and is expected to be critical [5]-[7].

With the continuous evolution of scaling, the need to evaluate new designs and technologies against direct ionization is of concern. Nowadays, the appropriate energies for measuring direct ionization SEE lies in the 1 to $3 \mathrm{MeV}$ range. Moreover, the adequate flux range is quite narrow: lower limit is set by the device response and sensitivity (test fluence defines the test duration), the upper limit shall account for tester capabilities (detection rate) and device dose resistance.

Only few facilities exists that can deliver appropriate energy-flux characteristics. ONERA started developing the Mirage beam line at DESP for electronics applications (proton and electron dose in optoelectronics and photonics) in 2008. New beam developments (for direct ionization thematic) have been carried out in 2012 and finalized in 2013 (with the support of CNES).

\section{MiRAGE TARGET CHAMBER}

\section{A. Description}

The DESP department at ONERA runs two van de graaff accelerators $(\mathrm{VdG})$ for materials and components activities.
These machines are connected to the MIRAGE target chamber providing the capabilities to test devices with electron and proton with the same facility.

Originally, MIRAGE was developed for testing devices against (ionizing or non-ionizing) dose effects.

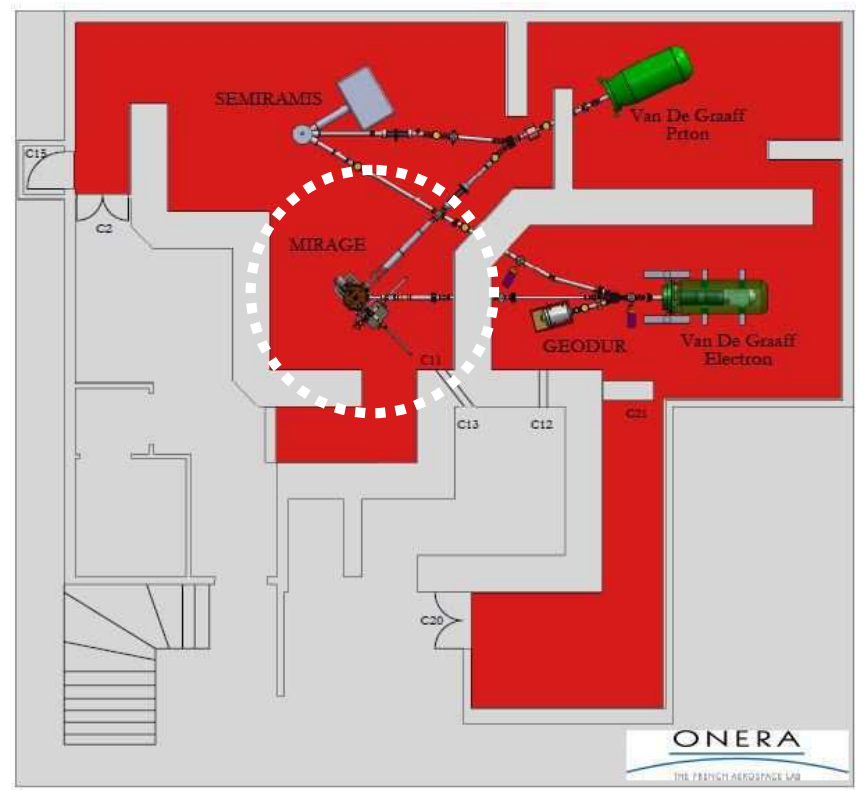

Figure 1 - the accelerators and beam lines at ONERA-DESP (Mirage is highlighted with broken white line)

The standard beam capabilities at Mirage are:

- Species : electron or proton,

- Machine energies : resp. 2.5 and $2 \mathrm{MeV}$,

- Beam current: 1 to $80 \mathrm{nA}$ on target (flux of $6 \times 10^{9}$ to $5 \times 10^{11}$ part. $\left./ \mathrm{cm}^{2} . \mathrm{s}\right)$,

- Homogeneity $10-15 \%$ on $120 \mathrm{~mm} \times 120 \mathrm{~mm}$,

- Motorized table (z, $\theta)$,

- Temperature monitoring $\left(-150^{\circ}\right.$ to $\left.+250^{\circ}\right)$.

B. Proton line: overview of the $V d G$ operation and beam monitoring (details in Figure 6)

The proton beam is extracted from plasma created with $\mathrm{H}_{2}$ gaz and RF source. This plasma is originally made of a mixture of $\mathrm{H}+, \mathrm{H}_{2}{ }^{+}$and $\mathrm{H}_{3}{ }^{+}$ions which are accelerated at first by a focus stage then injected into the acceleration tube.

At the output of the machine, a bending magnet acts as a mass spectrometer and allows for selecting $\mathrm{H}^{+}$with the correct current setting (calculated from the magnet characteristics for a 
given energy) to deviate protons into the MIRAGE beam line at $25^{\circ}$.

The beam energy is therefore defined (and adjusted) by the acceleration voltage and bending magnet current with great accuracy (few\%).

The beam monitoring down the line is then ensured $\mathrm{XY}$ quadruples magnets and 3 steerers. Finally, the beam is $X Y$ swept on target where dosimetry is ensured by means of 5 faraday cups (FC, cups at central and four corners position of a $65 \mathrm{~mm} \times 65 \mathrm{~mm}$ square, adjustable in position, see Figure 2) and scintillators (SC)

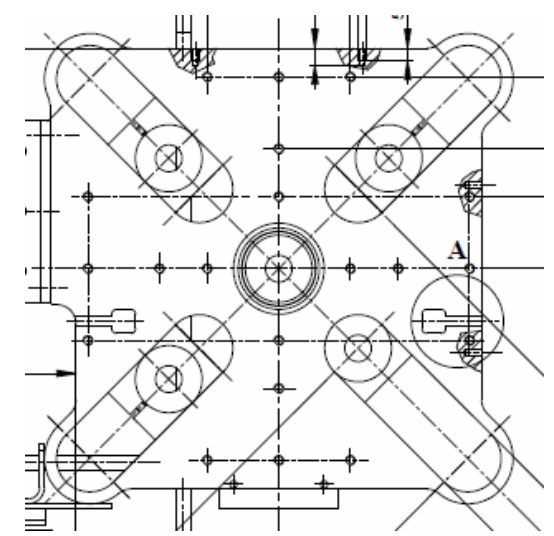

Figure 2 - sample holder with the central FC and 4 adjustable positions at 4 corners.

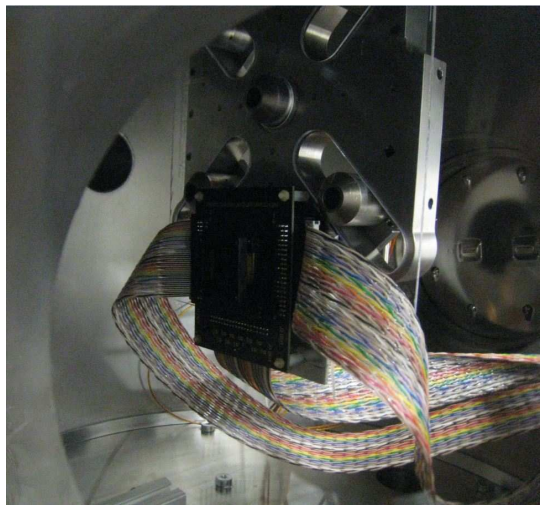

Figure 3 - example of test board mounted on the holder (courtesy TRAD)

An automatic control system allows for remote command and control of the accelerator (injector, voltage, vacuum, temperature...) and line systems (collimators, sweeper \& bending magnets, steerers, shutters, faraday cups, imaging devices ...).

The following picture shows the labview interface allowing for the monitoring of the main beam parameters. Main window discloses FC parameters (sizing, gain and filtering of acquisition chain, top left) and measured currents (central display, red bars). Also enclosed, the XY sweeping feature of the beam (bottom left).

The acquisition chains include the possibility to select adequate converter factor (low or medium factors) and have been calibrated using 9pA current source leading to an accuracy on current measurements of $2-3 \%$.

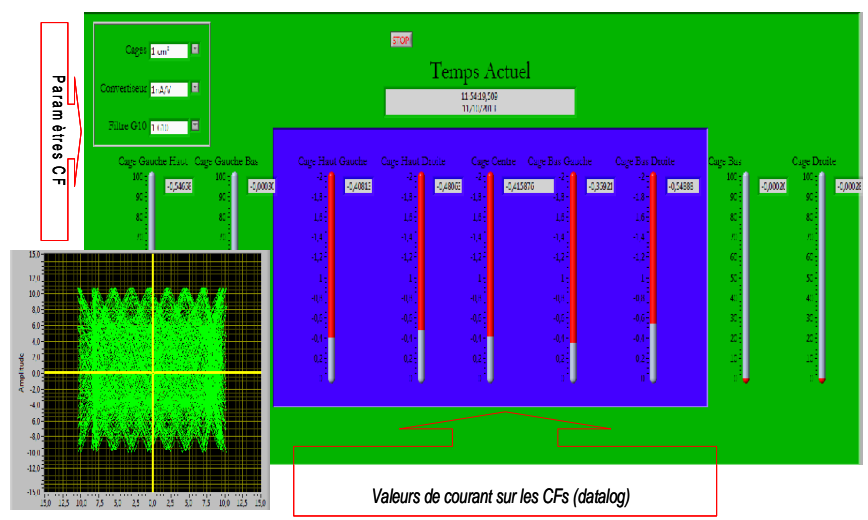

Figure 4 - Labview interface for beam monitoring. Bottom left: phase/amplitude of the sweeping system.

\section{Low current beam configuration}

In 2012, the development of low beam flux configuration have started in order to address the new thematic of direct ionization-induced SEE. The requirements disclosed in TABLE 1 have been defined.

TABLE 1

REQUIREMENTS FOR LOW CURRENT BEAM

\begin{tabular}{|l|l|l|}
\hline parameter & criteria & comment \\
\hline energy & $\begin{array}{l}\text { mono-energetic, } \\
\text { adjustable up to } \mathrm{E}_{\max }\end{array}$ & $\begin{array}{l}\text { typical range in } \mathrm{Si}: 10- \\
47 \mu \mathrm{m}\end{array}$ \\
\hline flux & $\begin{array}{l}\text { adjustable (few } 10^{6}-10^{9} \\
\left.\# / \mathrm{cm}^{2} . \mathrm{s}\right)\end{array}$ & depends on device response \\
\hline fluence & $10^{8}-10^{10} \# / \mathrm{cm}^{2}$ & $10 \%$ \\
\hline homogeneity & $15 \%$ on spot size & $10 \%$ on die area \\
\hline Beam spot & $65 \mathrm{~mm}$ x $65 \mathrm{~mm}$ & $>$ die area \\
\hline tilt & $0^{\circ}-60^{\circ}$ & limited by min range \\
\hline Feed-through & standard connectors & $\begin{array}{l}\text { BNC, Jaeger, SMA, HE10- } \\
40(\mathrm{x} 3)\end{array}$ \\
\hline
\end{tabular}

The MIRAGE beam line has been adapted for low current beam configuration mixing different techniques as disclosed in Figure 5:

- minimizing the ion current at source level (low injection controlling gaz injection, extraction level and focalisation),

- collimating / un-focalising (at ion and proton levels),

- sweeping the beam (before the target chamber).

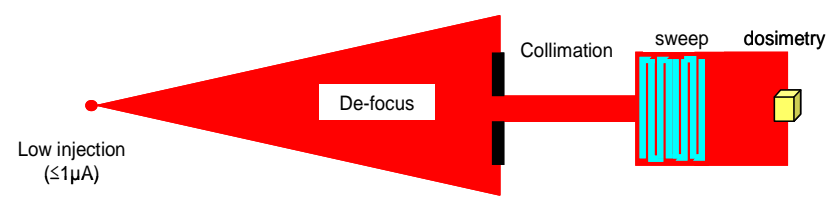

Figure 5 - Approach used for the low current beam configuration 


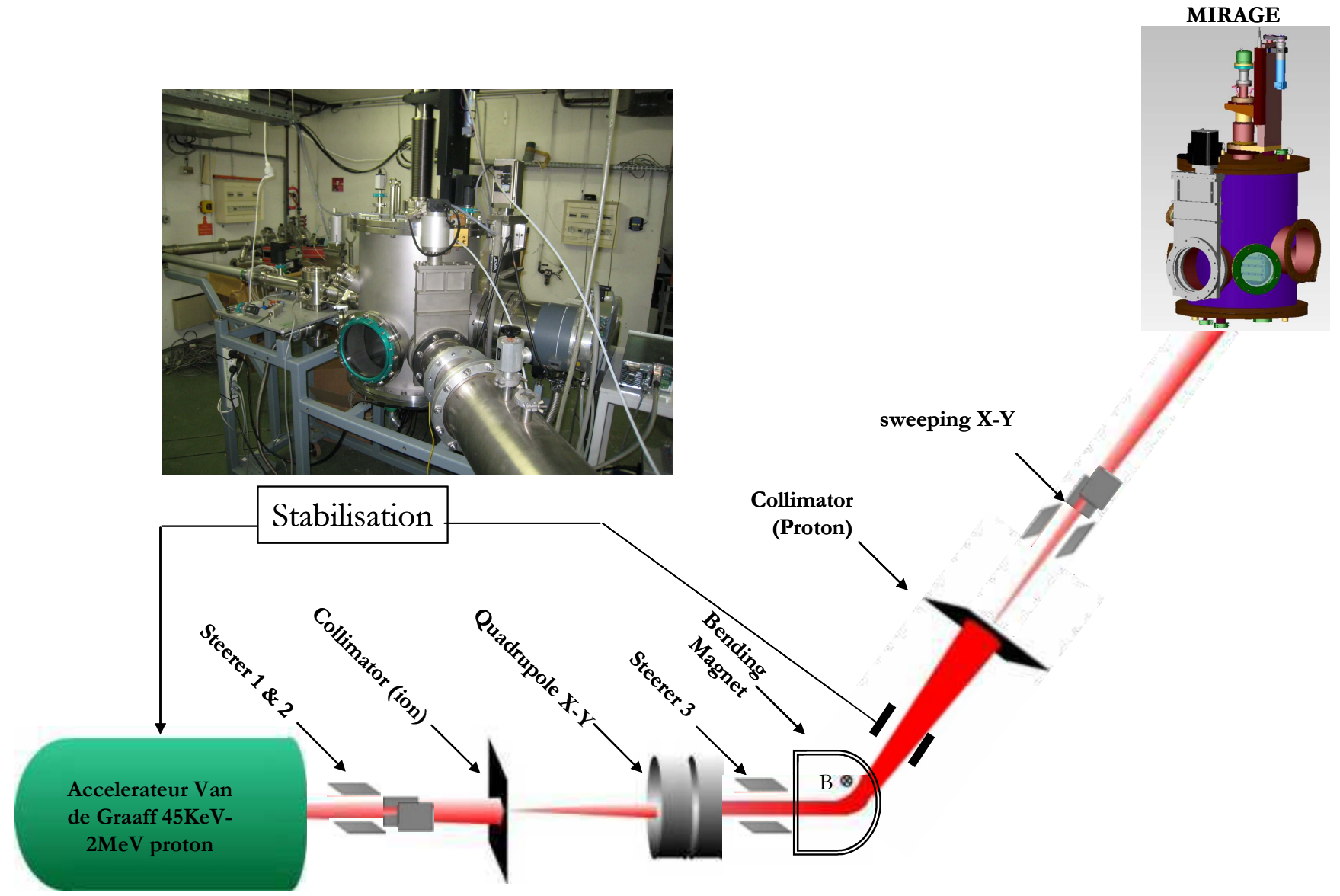

Figure 6 - Mirage proton beam line: overall configuration

\section{TESTS AND VALIDATION}

\section{A. Validation with faraday cups measurements}

Beam validation has been carried out end of 2013. Measurements with different collimator sizes (1,2 and $5 \mathrm{~mm}$ ) and energies in the 0.8 to $1.7 \mathrm{MeV}$ range and for different injection levels have been carried out to validate the approach and define beam adjustment procedure. Some measurements are disclosed on Figure 8 and Figure 8 for a $1.5 \mathrm{MeV}$ proton beam.

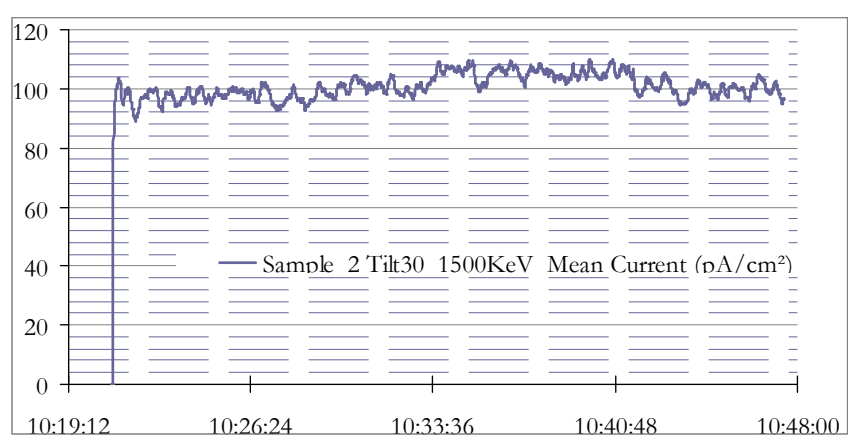

Figure 7 - current versus time for a $100 \mathrm{pA} / 1500 \mathrm{keV}$ proton beam $\left(6.24 \times 10^{8}\right.$ protons $\left./ \mathrm{cm}^{2} . \mathrm{s}\right)$
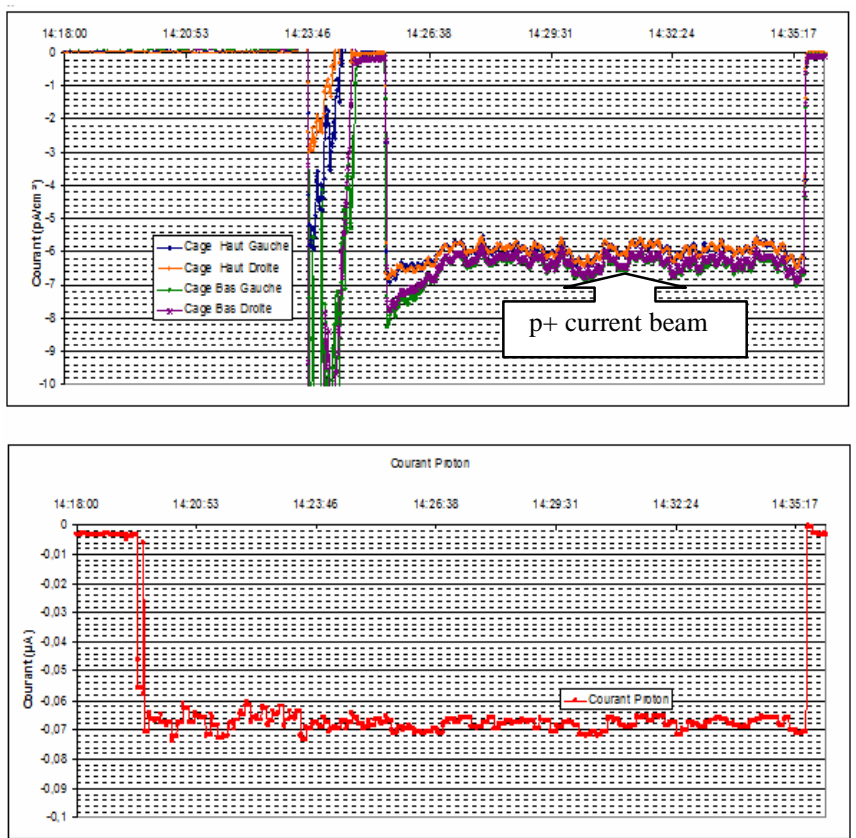

Figure 8 - current versus time for a $6 \mathrm{pA} / 1500 \mathrm{keV}$ proton beam (middle - proton current equivalent to $3.7 \times 10^{7}$ protons $/ \mathrm{cm}^{2} . \mathrm{s}$, bottom - corresponding beam current at injector level).

It can be noticed that beam is homogeneous (same current level measured here by the 4 FCs - top graph) and stable with time (Figure 7 and Figure 8 bottom). 


\section{B. Validation based on Silicon PIN Diode}

Complementary experiments based on PIN diode were performed. The readout test system consists of a pair of silicon PIN diodes, pre-amps and shaping amplifiers, a discriminator, and a MCA (DSA1000 from Canberra). The acquisition chain of the detector was calibrated using alpha-emitting isotope ${ }^{241} \mathrm{Am}$ source (in a vacuum chamber, the source placed at $2 \mathrm{~cm}$ from the silicon sensor).

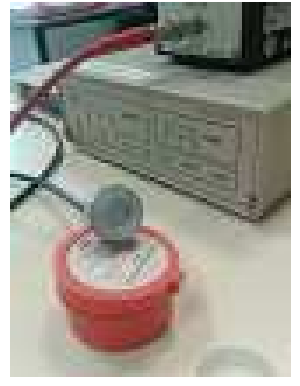

Figure 9 - Bancal system (PIN diode detector)

The silicon PIN diode is made of an active area of $1 \mathrm{~cm}^{2}$ (high resistive $\mathrm{N}$-type diode $300 \mu \mathrm{m}$ thick) that can be fully depleted by applying reverse bias voltage (up to 60V). One of advantages of the full depletion is that silicon bulk can be used as an active volume sensor. Electron-hole pairs produced by protons passing through the silicon bulk induce a charge collection on the electrodes due to the electric field created by the reversed bias. Electrons are collected in ohmic $(\mathrm{N}+)$ side and holes are collected in the front $(\mathrm{P}+)$ side by the bias voltage.

The energy spectrum from Mirage proton beams were measured with the PIN diode collimated to limit pile up effects. For a given configuration, the proton mean flux level measured with the faraday cups is $1.8 \times 10^{7}$ proton $/ \mathrm{cm}^{2}$.s to be compared to the output of the acquisition chain of the PIN diode measured at $1.2 \times 10^{7}$ proton $/ \mathrm{cm}^{2} . \mathrm{s}$.

\section{Test campaigns}

Two test campaigns have been organized to test $45 \mathrm{~nm}$ FPGA (TRAD testing with CNES support), perform crosscomparison with CNA results and measured device response at different tilt angles. Detailed results are disclosed in [8] showing good agreement between data (Figure 10). Particularly the Bragg peak-like feature of the cross section curve could be completed and tilt response investigated.

Figure 10

Another test campaign has been performed with CEA on Memory testing (90nm Cypress technology) in order to complete a set of data with neutrons, heavy ions and high energy protons that will be published in the near future.

\section{CONCLUSIONS}

A new proton beam line has been developed at ONERA for investigating radiation effects in electronics. Standard beams are used for studying cumulated effects in optoelectronics and photonics, low current configuration has been developed for studying direct ionization effects in advanced digital technologies.

The numerous tests and measurements performed during the validation phase with the new MIRAGE low current proton beam configuration have shown:

- the possibility to perform SEE testing in the 0.5 to $2 \mathrm{MeV}$ range with flux of few $10^{6}$ to $10^{9}$ proton $/ \mathrm{cm}^{2}$.s with 10 to $15 \%$ of homogeneity on an beam spot area of $65 \mathrm{~mm} \mathrm{x}$ $65 \mathrm{~mm}$ (homogeneity much better than $10 \%$ ensured on standard target size of $20 \mathrm{~mm} \times 20 \mathrm{~mm}$ ),

- good beam stability in terms of beam current and energy over long period of time (>hour),

- a good reproducibility of beam parameters,

- a rapid adjustment of beams (15-20 minutes to change energy or flux).

Test campaigns will be regularly organised on this beam line to help investigating sub-100nm digital device sensitivity to direct ionisation. Improvement of the facility is also planned with optimized real time counting, new frame and positioning system.

\section{REFERENCES}

[1] Heidel D.F., Marshall P.W., LaBel K.A., Schwank J.R., Rodbell K.P., Hakey M.C., Berg M.D., Dodd P.E., Friendlich M.R., Phan A.D., Seidleck C.M., Shaneyfelt M.R., Xapsos M.A., "Low Energy Proton Single-Event-Upset Test Results on 65nm SOI SRAM", IEEE TNS., Vol. 55, No. 6., 2008.

[2] D. F. Heidel, K. P. Rodbell, E. H. Cannon, C. Cabral Jr., M. S. Gordon, P. Oldiges, H. H. K. Tang, "Alpha-particle-induced upsets in advanced CMOS circuits and technology", IBM J. RES. \& DEV., Vol. 52, No. 3, 2008.

[3] D. F. Heidel, P. W. Marshall, J. A. Pellish, K. P. Rodbell, K. A. LaBel, J. R. Schwank, S. E. Rauch, M. C. Hakey, M. D. Berg, C. M. Castaneda, P. E. Dodd, M. R. Friendlich, A. D. Phan, C. M. Seidleck, M. R. Shaneyfelt, M. A. Xapsos, "Single Event Upsets a,d Multiple-bit upsets on a $45 \mathrm{~nm}$ SOI-SRAM", IEEE Trans. Nucl. Sci., Vol. 56, No. 6, pp. 3499-3504, Dec. 2009

[4] R. K. Lawrence, J.F. Ross, N.F. Haddad, R.A. Reed, D.R. Albrecht, "Soft Error Sensitivities in 90nm Bulk CMOS SRAMs", Radiation Effects Data Workshop, NSREC 2009, pp. 71-75.

[5] G. Hubert, S. Duzellier, F. Bezerra, R. Ecoffet, "MUSCA SEP3 contributions to investigate the direct ionization proton upset in $65 \mathrm{~nm}$ technology for space, atmospheric and ground applications", RADECS 2009.

[6] B.D. Sierawski, J.A. Pellish, R.A. Reed, R.D. Schrimpf, K.M. Warren, R.A. Weller, M.H. Mendenhall, J.D. Black, A.D. Tipton, M.A. Xapsos, R.C. Baumann, X.Deng, M.J. Campola, M.R. Friendlich, H.S. Kim, A.M. Phan, and C.M. Seidleck, "Impact of Low-Energy Proton Induced Upsets on Test Methods and Rate Predictions", IEEE TNS., Vol. 56, No. 6., 2009, pp. 3085-3092.

[7] G. Hubert,S. Bourdarie, L. Artola, S. Duzellier, C. Boattela-Polo, F. Bezerra, R. Ecoffet, "Impact of the Solar Flares on the SER dynamics on Micro and Nanometric Technologies in the Geostationary Orbit", IEEE Trans. Nucl. Sci., Vol. 57, No. 6, pp. 3127-3134, Dec. 2010.

[8] Nicolas Sukhaseum et al., "A Calculation Method for Proton Direct Ionization Induced SEU Rate from Experimental Data: Application to a Commercial 45nm FPGA", accepted as a poster at nsrec 2014. 